\title{
A CONDUTA MÉDICA E A \\ CARACTERIZAÇÃO DO ERRO
}

Graziela Gobbato"

SUMÁRIO: 1. Introdução. 2. Responsabilidade Civil e o erro Médico. 3. Conclusão. 4. Bibliografia.

SUMMARY: 1. Introduction. 2. Civil Responsibility and the Medical Error. 3. Conclusion. 4. Bibliography.

SUMARIO: 1. Introducción. 2. 2. Responsabilidad civil y el Erro Médico. 3. Conclusión. 4. Bibliografia.

RESUMO: Este artigo vislumbra uma apreciação teónica sobre a conduta médica e a caracterização do erro no exercicio da profissão de medicina, modo pelo qual, o reconhecimento do erro propriamente dito, dá-se através da submissão aos atos de prestação de serviços ao paciente, onde especialistas com competência disciplinar atuam. O confronte do erro médico ocorre juridicamente, através da junção de provas, do refinamento dos fatores que causaram o eventual erro, dano ou lesão ao paciente. Teoricamente, técnicas, métodos, consciência e conhecimento científico utilizados para o sucesso do trabalho, isentam o profissional de eventuais erros médicos, porém, na ocorrência e comprovação de imperícia, imprudência e negligência, a probabilidade de confirmação do erro torna-se capaz de responsabilizar o profissional civilmente por resultados năo esperados pelo paciente atendido, o que poderá transformarse em reexecução ou indenização. 
ABSTRACT: This article discerns a theoretic idea about the medical conduct and the mistake features on this profession, so that the recognition of the mistake itself happens though submitting the service acts to the patient, where disciplinary competent specialists perform. The medical mistake is faced by juridical means, through the gathering of proof, refining of the factors that caused the eventual mistake, damage or injury to the patient. Theoretically, techniques, methods, conscience and scientific knowledge used to achieve the success of the performance exempt the professional from eventual medical mistakes; however, with the occurrence and evidence of unskilfulness, imprudence and negligence the probability of confrrming the mistake is able to make the professional civilly responsible for the patient's unexpected results, what might imply in re-execution or indemnity.

RESUMEN: El articulo conjetura una apreciación teórica de la conducta medica y la caracterización del error en el ejercicio de la profesión de la medicina, el modo por el que, el reconocimiento del error dicho, ocurre través de la sumisión a los actos de prestación de servicios al paciente, donde especialistas con capacitación disciplinar actúan. La confrontación del error medico ocurre jurídicamente, través de la junción de pruebas, del refinamiento de los factores que causaran el eventual error, daño o lesión al paciente. En teoria, técnicas, metodologías, conciencia y conocimiento cientifico utilizados para el suceso del trabajo, exentan el profesional de eventuales errores médicos, pero, en la ocurrencia y comprobación de la impericia, imprudencia y negligencia, la probabilidad de la confirmación del error tornase capaz de responsabilizar el profesional con una acción civil por los resultados no esperados por el paciente atendido, el que podrá transformarse en "reejecución" o indemnización.

PALAVRAS-CHAVE: Médico. Paciente. Erro médico. Conduta. Responsabilidade. 
KEY-WORDS: Doctor. Patient. Medical mistake. Conduct. Responsibility,

PALABRAS-LLAVES: Medico. Paciente. Error médico. Conducta. Responsabilidad.

\section{Introdução}

A caracterização do erro médico está relacionado ao vínculo do profissional e o exercício da prática médica, e, que por ocasião do atendimento ao paciente exista a comprobatoriedade da lesão, do dano ou da seqüela ocorrida em virtude da prestação dos serviços realizados. No entanto, observa-se também que a combinação destes fatores permeia responsabilidade, ação indenizatória ou reexecução do trabalho, nos casos de cirurgia plástica. Porém, devido a grande condição de precariedade da vida humana, em que aplicando todo esforço, ainda assim, não é capaz. de produzir resultado razoável ${ }^{1}$, cabe considerar o enquadramento da responsabilidade médica dentro da teoria subjetiva, uma vez que o organismo não oferece certeza para a execução do trabalho, o que fará a isenção da culpabilidade dentro dos limites esgotados pelo emprego de todos os meios possíveis para a realização de um bom trabalho. ${ }^{2}$

Sabe-se todavia, que peculiaridades tais como conhecimento técnico, consciência na realização do trabalho, perícia e prudência invalidam o erro médico, bem como os casos em que houve dificuldade de diagnosticar uma maior gravidade no estado do paciente devido às questóes inerentes ao próprio caso. O Código de Ética Médica e demais legislações brasileiras abordam relevantes posicionamentos no que concerne aos deveres $\mathrm{e}$ obrigaçôes do profissional para com o paciente. Dentre estes, convém ressaltar a necessidade da obrigação de informar ao paciente sobre os eventuais riscos na modalidade do tratamento pelas quais irá passar, assegurando e anotando os processos e os meios utilizados, os cuidados e os procedimentos necessários em virtude da submissão ao tratamento, o que irá contribuir para o afastamento do insucesso, mau resultado ou resultado inesperado pelo paciente.

GIOSTRI, Hildegard Taggesell. Responsabilidađe Médica. As Obrigaçós de meio e de resultado: Avaliaça, Uso e Adequação. Tese apresentada no Curso de Pós-Graduação em Direito, do Setor de Ciências Juridicas da Universidade Federal do Paraná. 2000.

${ }^{2}$ Idem, 


\section{Responsabilidade Civil e o Erro Médico}

A responsabilidade médica tem sido preocupação constante das ciências jurídicas, motivo pelo qual a matéria que vem sendo discutida e aprimorada, vastamente debatida, seja no campo civil, penal ou mesmo ético.

Observa-se, no entanto, que a prevenção de certas medidas em relação à conduta médica desperta êxito nos procedimentos finais. Posicionamentos temáticos tem se levantado em torno da atuação do profissional médico, deflagrado pelo surgimento e aplicação das normas constantes do Código de Defesa do Consumidor (CDC), que em outrora foi assunto de calorosos embates.

Não apenas o profissional médico, mas todo aquele que no exercício do cumprimento do seu dever, deve realizar o bem e não o faz comete ato lesivo, vindo este a diminuir outrem contra sua vontade, inibindo os seus direitos. O dever jurídico da responsabilidade pode basear-se em contrato, fato ou omissão, advindo, assim, tanto da convenção como da norma jurídica. Pode, pois, a responsabilidade civil, singelamente, definirse como a obrigação de reparar o prejuízo causado a alguém. ${ }^{3}$

Para que o erro médico fique caracterizado, faz-se necessário a evidência de uma falha no exercício da profissão, e, para haver a possibilidade de erro, é necessário que haja uma referência padrão do que correto e belo, havendo assim um parâmetro de julgamento ${ }^{4}$, transcendendo considerações evidentes de descuidos ou incompetência médica às regras de sua arte, ${ }^{5}$ em conseqüência ao comprometimento total ou parcial da vida do paciente atendido pelas mão do profissional.

O erro médico pode ser visto com pouca ou grande diferença, basta que tenha atingido o objetivo visado por ocasião da contratação do serviço. ${ }^{6} \mathrm{Na}$ cirurgia estética, a cura, seria, sem dúvida, a ausência de anomalia, da modificação do perfil inicial, dirigida para o embelezamento do ser, gozando este, de pleno bem-estar e jovialidade, oferecendo conforto inclusive ao próprio profissional que sentir-se-á bem quando sua consciência estiver tranqüila.

A responsabilidade civil trata da aplicação de medidas que obriguem uma pessoa a reparar o dano moral ou patrimonial causado a terceiros,

\footnotetext{
CROCE, Delton Jr. \& CROCE, Delton. Erro Médico e o Direito. 2\%. ed. São Paulo: Editora Saraiva, 2002. 4 MORAES Irany Novah. Erro Médico e a Lei. 4\%. ed. Säo Paulo: Livaria e Editora Juridica Senador. 1998. p. 305. SAMPAO \& SILVERA LEAL. Ementa Responsabilicide Cvil. 3 , ed. Rio de Janeiro Editora Fsplanada. 1999, p. 101. "Ib. p. 308 .
} 
em razão de ato por ela mesma praticado, por pessoa por quem ela responde, por alguma coisa à ela pertencente ou de simples imposição legal.

Portanto, havendo um dano ou prejuízo, haverá de ser responsabilizado o causador do mesmo, para que indenize o lesado. Assim, se, por um lado, encontra dificuldade a doutrina para conceituar responsabilidade civil, por outro lado, é fácil o entendimento das conseqüências e práticas que a mesma faz surgir nas relações sociais. A exigência de reparar o dano, é sem dúvida, em todos os tempos, a obrigação de reparar um certo prejuízo causado, questionamento que surge divergência, originando correntes que dividem autores, fundamentando-se no dever ressarcitório, dando lugar à teoria objetiva e subjetiva inspirados no risco e na culpa.

A essência da responsabilidade baseada na teoria subjetiva, vem assentarse fundamentalmente na pesquisa ou indagação de como o comportamento humano contribui para o prejuízo sofrido pela vítima e não apenas a conduta do médico. Assim procedendo, não considera apto a gerar o efeito ressarcitório um fato humano qualquer. Somente será gerador daquele efeito uma determinada conduta, que a ordem jurídica reveste de certos requisitos ou de certas características.

Assim considerando, a teoria da responsabilidade subjetiva erige em pressuposto da obrigação de indenizar, ou de reparar o dano, o comportamento culposo do agente, ou simplesmente a sua culpa, abrangendo no seu contexto a culpa propriamente dita e o dolo do agente.

A culpa, em um dado episódio danoso pode até ser do lesante, do lesado, ou de ambos, lesante e lesado. Se houve uma parcela de culpa de cada um na ocorrência do prejuízo, pela teoria subjetiva aplicada ao caso, será atribuído proporcionalmente o ônus da recomposição, na medida exata da contribuição de cada um no resultado final danoso.

Sobrepõe-se, neste contexto, que o profissional médico deve ser portador de autoridade para o desempenho da função inerente, atribuindo responsabilidade específica aos seus atos. A negligência no atendimento ao dever de médico, contribui, de forma eficaz para o enlace da culpa e da responsabilidade, devendo este, responder à altura, pelas conseqüências danosas em virtude da omissão ou imprudência.

O processo pelo qual o médico pode isentar-se de eventuais problemas relativos ao atendimento, é manter-se preparado com registros desde o momento da consulta, exames e procedimentos cirúrgicos até os 
atendimentos finalizantes, constituindo-se em documentação que justifiquem seus atos. Sobretudo, porque a inobservância de regra técnica, na arte do ofício de médico cirurgião plástico culmina em agravamento, o que não poderá ser confundido com imperícia, constituindo-se numa modalidade de culpa, sendo o responsável, indiferente aos conhecimentos técnicos recebidos, empregando-os com leviandade. 7 A responsabilidade civil, é a obrigação que pode incumbir a uma pessoa (profissional) de reparar o prejuizo causado a outrem por fato seu, ou pelo fato das pessoas ou das coisas dela dependentes A responsabilidade civil médica, portanto, nada mais é do que a obrigação do médico ou da clínica responsável, de arcar com os prejuízos causados a outrem, quando houver a comprovação de danos decorrentes da atuação destes profissionais.

Todavia, na conduta médica está implícita a obrigação de resultado, porém, Aníbal Bruno apud $\mathrm{CROCE}^{8}$ compreende ser erro escusável e não imperito aquele que empregando correta e oportunamente aos conhecimentos e regras que a ciência domina, postulando uma conclusão falsa ao profissional. Outro modo de isenção de responsabilidade, é a concretização de situações hipotéticas e imprevisíveis, conjeturando maior diligência nas questões que requeiram uma maior importância.

E coerente o pensar que a responsabilidade do profissional esta intimamente ligada com a arte de curar, de estabelecer melhora no tocante à doença e efetivar a promoção do mesmo para a cura.

Dentre os danos advindos das cirurgias ou procedimentos médicocirúrgicos podem-se destacar aqueles de ordem estética e os oriundos da aflição moral do paciente/consumidor. Tais questionamentos são de muita importância para a composição dos danos provenientes de atos que tenham como conseqüência prejuízos à morfologia humana. $\mathrm{O}$ paciente, ao procurar um profissional para realizar exames, tratamentos ou mesmo intervençôes cirúrgicas, está, na verdade, firmando convenções.

Neste posicionamento é possível discutir as obrigações envolvidas nos contratos de prestação de serviços médicos, se são elas de meio ou de resultado. De maneira geral, aborda-se que o contrato médico envolve obrigação de meio, principalmente quando se está diante de cirurgias complicadas e com alto grau de periculosidade. 
Por outro lado, vê-se crescente, o movimento que afirma ser obrigação de resultado determinados contratos médicos, como os que visam o melhoramento estético de determinada pessoa (cirurgia plástica não reparadora).

Neste caso, devido ao alto grau de avanço tecnológico, afirma-se, ser mínima a possibilidade de não alcance do resultado visado na cirurgia.

Mais modernamente', segundo o Código de Defesa do Consumidor, a responsabilidade pessoal dos profissionais liberais será apurada mediante a verificação de culpa, temperando-se pela inversão do ônus da prova, no processo civil, em favor do consumidor. A erro médico na responsabilidade civil ou patrimonial do médico por atos de seu oficio, fundamenta-se na responsabilidade contratual e na culpa, sendo indisputável a caracterização do dano material ou moral, o nexo de causalidade e a inexistência das hipóteses de excludentes da culpabilidade: caso fortuito e força maior.

O dano estético, por sua vez, é conceituado como toda alteração morfológica do indivíduo que, além do aleijão, abrange as deformidades ou deformações, marcas e defeitos, ainda que mínimos, e que impliquem sob qualquer aspecto um afeiamento da vítima, consistindo numa simples lesão desgostante ou num permanente motivo de exposição ao ridículo ou de complexo de inferioridade, exercendo ou não influência sobre sua capacidade laborativa. ${ }^{10}$

A lesão estética, em regra, constitui-se, indubitavelmente, um dano moral que poderá ou não constituir um prejuízo patrimonial. Seguindo-se esta linha de raciocínio, o dano moral sempre abrangerá o estético ou morfológico, quando o prejuízo for extrapatrimonial, pois este último, é espécie do primeiro.

Observa-se um exemplo que vem demonstrar com clareza tal assertiva. Uma profissional manequim que venha necessitar de seu belo rosto e corpo para poder ter o seu sustento, em uma determinada cirurgia plástica, vem essa modelo a sofrer lesões que causem deformidades permanentes em sua morfologia (corpo e rosto), impedindo-a de trabalhar, por falta de ofertas de emprego. Nesta hipótese, vislumbra-se com clareza dois tipos de prejuizos, um de ordem extrapatrimonial, e outro de ordem patrimonial.

Segundo Aguiar Dias, a doutrina e a jurisprudência inclinam-se para admitir que a obrigação a que está submetido o cirurgião plástico não é diferente daquela dos demais cirurgiões, pois corre os mestnos riscos e depende da mesma álea. ${ }^{11}$ Seria, portanto, como a dos médicos em geral, uma obrigação de meio. ${ }^{12}$

\footnotetext{
"Código de Defesa do Consumidor. Art. 14, $\$ 4$ ".

19 MORAES, Irany Novah. Erro Medico a Lei. 4\% ed. Säo Paulo: Livraria e Editora Juridica Senador. 1998.

"DLAS, p. 121. apud GIOSTRL, Hildegard Taggesell. Responsabilidade Medica. As Obrigaçôes de Meio e de Resultado: Avaliaçăo, Uso e Adequação. Tese apresentada no Curso de Pós-Graduação em Direito, do Setor de Ciências Juridicas da Universidade Federal do Paraná. 2000.

iz AGUAR Jr, Ruy Roxado de Responsabilidade Civi Módica RT 718/39 citalo por Rui 5txo (Ob. cit). Fditora Saraiva 2002
} 
A cirurgia plástica, com fins exclusiva ou preponderantemente estéticos, é cirurgia embelezadora e, por isso, a obrigação não é de meio e sim de resultado. Na hipótese de o resultado ser negativo e oposto ao que foi convencionado, presume-se a culpa profissional do cirurgião, até que ele prove sua não-culpa ou qualquer outra causa exonerativa. Inobstante o fumar no período pós-operatório possa provocar os danos ocorridos, há necessidade de o réu provar que a cliente fumou, embora a contra-indicação médica seja prova suficiente e a responsabilidade civil seja reconhecida. ${ }^{13}$

O erro médico, frente ao Código de Defesa do Consumidor, elabora esferas dispostas também no Código de Ética, cujas infrações, podem transformar-se em processos tanto de ordem civil quanto criminal. ${ }^{14}$

Normalmente, ao se tratar de erro médico, observa-se que está relacionado ao infringimento dos princípios fundamentais, porém, muitas especialidades são de risco, o que invoca a relação de causa e efeito, e, muitas vezes, entre a tomada de decisão e o tempo em decurso contribuiu para o agravamento do caso o que poderá apresentar resultado não esperado, sendo assim, poderá isentar a responsabilidade do médico. ${ }^{15}$

Como exemplo, tem-se a cirurgia plástica, que é o objeto principal de estudo dessa dissertação, exercida sob a perspectiva legal como um contrato de meio e não de resultado, por visar, na maioria das vezes um resultado estético, por meio de ação cirúrgica, pretendendo um melhor aspecto fisico do paciente. ${ }^{16}$

A cirurgia estética, segundo doutrinadores do direito, por certo ângulo de visão évista, como "algo distante da necessidade", e sim de caráter puramente embelezador, o que possibilita o enquadramento na teoria subjetiva, imputando a culpa. ${ }^{17}$

Para a teoria subjetiva, a responsabilidade civil está embasada, em todos os casos, na presença certa de culpa por parte do agente do ato que causou o dano. Chamando-se por teoria subjetiva em virtude de estar caracterizada na pessoa um aspecto volitivo interno, ou, pelo menos, revelar-se, mesmo de uma maneira tênue, uma conduta antijurídica.

O agente do prejuízo quer o resultado danoso ou assume o risco de que ele ocorra, ou ainda atua com imprudência, negligência ou imperícia.

\footnotetext{
13 O Dano Estético", RT, São Paulo, 1980, p. 62. Prova Suficiente. Responsabilidade civil reconhecida" (TJRS, Ap.Cível nª 591.055.017, 1ํㅡâmara, Rel. Des. Tupinambá M. C. do Nascimento, j. 05.05.1992).

${ }^{1+}$ BERNARDI, Sílvia de Liz Waltrick. A Prática Médica e o Código de Defesa do Consumidor. 1. ed. Curitiba: Editora Gềnesis. 2000. p. 17.

${ }^{15}$ BERNARDI, Sílvia de Liz Waltrick. A Prática Médica e o Código de Defesa do Consumidor. 1․ ed. Curitiba: Editora Gênesis. 2000. p. 17. p. 20.

${ }^{16}$ Idem. p. 21.

${ }^{17}$ Idem. p. 21.
} 
Ocorreria, no primeiro caso, dolo e no segundo caso, culpa. A legislação admite-os, na prática, como equivalentes, com o nome comum de culpa.

A conduta do agente responsável pelo dano estaria sempre viciada pela culpa. Está, assim, esse agente obrigado a ressarcir o prejuízo quando seus atos ou fatos sejam lesivos a direito ou interesse alheio, desde que possa ser considerado culposo - com culpa - o seu modo de agir.

Como ensina Oscar Ivan Prux :

"A importância da culpa vem desde tempos remotos, sendo amparada na noção de que ninguém deve ser punido se não demonstrado que quis o dano (caso de dolo) ou que, por sua ação omissiva ou comissiva, deu ensejo a ele".

A teoria subjetiva fundamenta-se, como se observa, na responsabilidade, pois uma vez a culpa provada, ou em certos casos presumida, dá ensejo a uma indenização, encontrando respaldo, especialmente, no art. 186 do Código Civil Brasileiro. A essa teoria filiou-se o Código Civil pátrio. Por esse motivo, a princípio, a responsabilidade civil surgirá da comprovação de culpa, incidindo em todos aqueles que, de um ou outro modo, estejam ligados ao prejuizo causado.

Todavia, para a caracterização da culpa médica, basta a simples voluntariedade e espontaneidade de conduta, sendo portanto, a intenção praticamente que desnecessária, pois a culpa, ainda que levíssima obriga a se indenizar. Mesmo que, em se tratando de vida humana, não se admite culpa "pequena ou levíssima", sem a prova desse elemento subjetivo da responsabilidade civil, a culpa, tudo há de ser debitado ao infortúnio.

\section{Conclusão}

No desenvolver deste artigo observou-se que, em momentos distintos, os doutrinadores posicionam-se de forma gradativa, ficando a responsabilidade civil, progressivamente, bem individualizada, deixando lacunas quanto a sua autonomia dentro do ordenamento jurídico, espelhando-se todavia, no sistema jurídico francês, de forma que a conduta médica e a caracterização erro fica bem clara dentro das teorias objetiva e subjetiva, distinguindo-se portanto, muito bem uma da outra. Como regra, a responsabilidade subjetiva, esta baseada na culpa, a exemplo disso, o Código de Defesa do Consumidor, em certos momentos admite a responsabilização subjetiva, exigindo uma averiguação da culpa dos profissionais liberais. 
Compreende-se que o contratado se obriga a utilizar os meios adequados para alcançar um determinado resultado, sendo assim, o comportamento do profissional deve ser o de agir com clareza e especificidade propriamente dito, cumprindo com a obrigação àquele que se obrigou, porém, se na relação profissional que se processou, comportou-se de maneira adequada, compativel com o que foi contratado está isento de responsabilidade.

Conclui-se portanto, em outra plataforma, que dentro do compromisso de realizar um determinado ato médico para obter um resultado preciso, a relação jurídica se encontra como resultado, devido ao modo pelo qual contratou, pois, segundo Demongue, há como determinar quem é possuidor do ônus da prova. É concludente que for obrigação de meios, o ônus pertence ao paciente, mas se for obrigação de resultado, vai ocorrer a inversão do ônus da prova, cabendo o mesmo ao médico. Verifica-se também que o profissional ao assumir uma obrigação de meios e não de resultado, que implica numa configuração de que o médico não se obrigou a curar mas sim em agir em absoluta conformidade com as técnicas e procedimentos concernentes à profissão, tendo este ainda, o arbítrio para evocar esforços para alcançar a cura ou o embelezamento, mesmo que não a consiga como resultado.

\section{BIBLIOGRAFIA}

ALCANTARA, Hermes Rodrigues de. Responsabilidade Médica. São Paulo: Editora saraiva. 1971.

AGUIAR Jr, Ruy Rosado de. Responsabilidade Civil Médica. RT 718/39 citado por Rui Stoco (Ob. cit.). Editora Saraiva. 2002.

BERNARDI, Sílvia de Liz Waltrick. A Prática Médica e o Código de Defesa do Consumidor. 1‥ ed. Curitiba: Editora Gênesis. 2000. p. 17.

CROCE, Delton Jr. \& CROCE, Delton. Erro Médico e o Dircito. $2^{\circ}$. ed. São Paulo: Editora Saraiva, 2002.

DIAS, p. 121. apud GIOSTRI, Hildegard Taggesell. Responsabilidade Médica. As Obrigações de Meio e de Resultado: Avaliação, Uso e Adequação. Tese apresentada no Curso de Pós-Graduação em Direito, do Setor de Ciências Jurídicas da Universidade Federal do Paraná. 2000. GIOSTRI, Hildegard Taggesell. Responsabilidade Médica. As Obrigações 
de meio e de resultado: Avaliação, Uso e Adequação. Tese apresentada no Curso de Pós-Graduação em Direito, do Setor de Ciências Jurídicas da Universidade Federal do Paraná. 2000.

MORAES, Irany Novah. Erro Médico e a Lei. 4․ ed. São Paulo: Livraria e Editora Jurídica Senador. 1998. p. 305.

O DANO Estético", RT, São Paulo, 1980, p. 62. Prova Suficiente. Responsabilidade civil reconhecida" (TJRS, Ap.Civel n ${ }^{\text {a }} 591.055 .017,1^{\text {o }}$ Câmara, Rel. Des. Tupinambá M. C. do Nascimento, j. 05.05.1992). SAMPAIO \& SILVEIRA LEAL. Ementa. Responsabilidade Civil. $3^{\circ}$. ed. Rio de Janeiro: Editora Esplanada. 1999. p. 101. 